\title{
Ganglioside GD3
}

National Cancer Institute

\section{Source}

National Cancer Institute. Ganglioside GD3. NCI Thesaurus. Code C39782.

A cell surface antigen expressed on all tumors of neuroectodermal origin, including melanoma, neuroblastomas, sarcoma, astrocytomas, and small cell lung cancer. GD3, an O-acetylated disialogang lioside, belongs to the group of glycosphingolipids that are widely expressed in many tissues and organs in vertebrates and have been suggested to be involved in the regulation of development and differentiation as recognition molecules or signal modulators. GD3 and GD2 gang liosides represent distinct and relevant immunotherapeutic target structures on melanoma, thereby both have the potential to be used as components of anti-melanoma vaccines. 